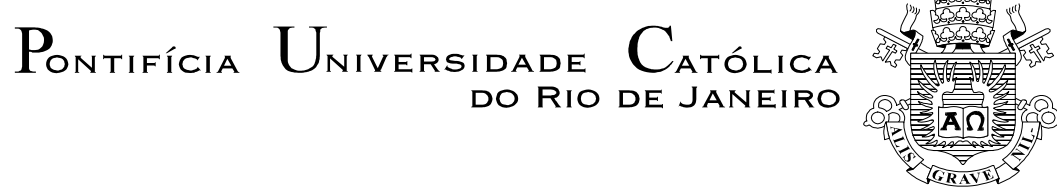

Marcos Fernandes de Souza

\title{
A EXPRESSÃO DO JEITINHO BRASILEIRO EM INTERAÇÕES VIA CALL CENTER
}

Tese de Doutorado

Tese apresentada ao Programa de PósGraduação em Letras do Departamento de Letras da PUC-Rio como parte dos requisitos parciais para obtenção em Letras.

Orientador: Profa. Dra. Maria do Carmo Leite de Oliveira 


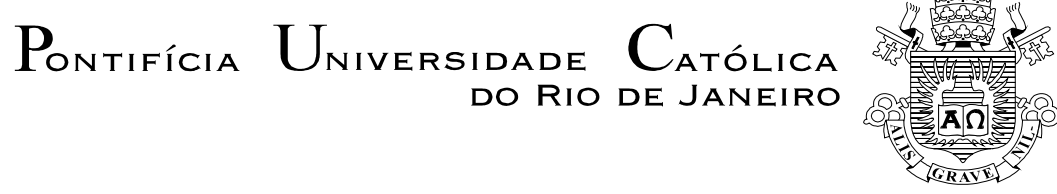

Marcos Fernandes de Souza

\section{A EXPRESSÃO DO JEITINHO BRASILEIROEM INTERAÇÕES VIA CALL CENTER}

Tese de doutorado apresentada ao Programa de Pós-Graduação em Letras da PUC-Rio como requisito parcial para obtenção do título de Doutor em Letras. Aprovada pela Comissão Examinadora abaixo assinada.

Profa . Dra . Maria do Carmo Leite de Oliveira

Orientadora

Departamento de Letras - PUC - Rio

Profa. Dra .Maria das Graças Dias Pereira

Departamento de Letras - PUC - Rio

Prof $^{a}$. Dra . Branca Falabella

Prof. Dr. Paulo Cortes Gago

Profa. Dra. Maria Claudia Coelho

UERJ

Prof. Dr. Paulo Fernando Carneiro de

Andrade

Coordenador Setorial do Centro de

Teologia e Ciências Humanas

Rio de Janeiro, 07 de janeiro de 2005 
Todos os direitos reservados. É proibida a reprodução total ou parcial do trabalho sem autorização da universidade, do autor e do orientador.

\section{Marcos Fernandes de Souza}

Bacharelado e Licenciatura em Letras na Universidade do Estado do Rio de Janeiro -UERJ em 1991. Defendeu Dissertação de Mestrado na PUC-Rio em 31 de agosto de 1999. É professor de Língua Portuguesa e Comunicação Empresarial em instituições universitárias privadas. Suas áreas de interesse são: Linguagem, Discurso em contexto de trabalho, Sociolingüística, Interacional, Análise da Conversação e Análise do Discurso.

Ficha Catalográfica

Souza, Marcos Fernandes de

A expressão do jeitinho brasileiro em interações via call center / Marcos Fernandes de Souza ; orientadora: Maria do Carmo Leite de Oliveira . Rio de Janeiro : PUC, Departamento de Letras, 2005.

239 f. ; $30 \mathrm{~cm}$

Tese (doutorado) - Pontifícia Universidade Católica do Rio de Janeiro, Departamento de Letras.

Inclui referências bibliográficas.

1. Letras - Teses. 2. Jeitinho brasileiro. 3. Cultura. 4. Identidade. 5. Narrativa. 6. Tecnologia. 7. Contexto. 8. Trabalho. 9. Cliente. I. Oliveira, Maria do Carmo Leite de. II. Pontifícia Universidade Católica do Rio de Janeiro. Departamento de Letras. III. Título. 
Dedico este trabalho à memória de meu pai, falecido neste primeiro semestre de 2005, na esperança de que, ainda me protegendo, me esteja sorrindo orgulhoso.

\begin{abstract}
À minha mãezinha, que é a minha grande inspiradora e guardiã da minha alma através de suas orações poderosas e da luz que dela me cobre como um manto sagrado.
\end{abstract}

À minha maravilhosa esposa pelo amor, força e dedicação, que jamais se apagarão do meu coração, sem ela este trabalho não teria sido possível, principalmente nas horas difíceis. 


\section{Agradecimentos}

Á minha orientadora Professora Doutora Maria do Carmo Leite de Oliveira pelos ensinamentos e pelo carinho que me conduziu à realização deste trabalho;

À PUC-Rio, pelos auxílios concedidos, sem os quais este trabalho não poderia ter sido realizado.

À minha família pelo apoio e motivação constante.

Às Professoras Doutoras Maria das Graças Dias Pereira, Liliana Cabral Bastos e Lúcia Pacheco.

À Professora Doutora Branca Falabella, especialmente, pela preciosa crítica e sugestão e ajuda, responsáveis pelo foco deste trabalho.

Ao Professor Doutor Paulo Cortes Gago, especialmente, pela crítica isenta, ajuda e companheirismo.

Aos professores da Comissão Examinadora.

A todos os professores e funcionários do Departamento de Letras, em especial a Chiquinha, pela presteza, compreensão e doçura.

Ao CNPQ, pela ajuda financeira para a pesquisa.

Às minhas amigas da PUC-Rio, Clarissa R. Bastos e Graça Salgado. 


\section{Resumo:}

Souza, Marcos Fernandes de; Oliveira, Maria do Carmo Leite de.

A Expressão do Jeitinho Brasileiro em Interações Via Call Center Rio de Janeiro, 2004. 239 p. Tese de Doutorado - Departamento de Letras, Pontifícia Universidade Católica do Rio de Janeiro.

Este trabalho trata das relações entre o contexto contemporâneo de trabalho, narrativas e identidade cultural brasileira. $\mathrm{O}$ estudo revelou que a realização de narrativas em centros de atendimento telefônico ao cliente (call center) é um dos meios lingüísticos pelos quais se pode expressar o "jeitinho brasileiro", um modo de comportamento cultural que é concebido como um traço de identidade da cultura brasileira. Os clientes utilizam o jeitinho para proteger seus pedidos de ação por parte da empresa ou para remover respostas despreferidas a esses pedidos. $\mathrm{O}$ jeitinho, além de ser um mecanismo de superação de dificuldades ou obstáculos, é um estilo de comportamento verbal caracterizado por estratégias indiretas de persuasão e por apelos aos sentimentos pessoais. Contudo, o call center, por sua natureza tecnológica, impessoal e inflexível, não permite que o uso das estratégias do jeitinho tenham sucesso. A lógica impessoal do call center é incompatível com a lógica pessoal do jeitinho. Tal confronto acarreta impactos emocionais no cliente e não atende a uma política de marketing voltada para o consumidor brasileiro.

Palavras-chave: jeitinho brasileiro, cultura, identidade, narrativa, tecnologia, contexto, trabalho, cliente. 


\section{Abstract:}

Souza, Marcos Fernandes de; Oliveira, Maria do Carmo Leite de. The Expression of the Jeitinho Brasileiro in Interactions via Call Center Rio de Janeiro, 2004. 239 p. Thesis - Departamento de Letras, Pontifícia Universidade Católica do Rio de Janeiro.

This work is about relationship between contemporaneous context of work, narrative and Brazilian cultural identity. The study revealed that the narrative realization in call center is one of the many linguistics ways where the Brazilian "jeito" can be expressed, a kind of cultural behavior that is conceived as a trace Brazilian cultural identity. The clients used the "jeitinho" so as to protect their requests or remove possible company barriers. Besides being a difficulty (or obstacle) surpass mechanism, the "jeitinho" is a verbal comportment style characterized by indirect strategies of persuasion that appeals to personal feelings. However, the call center, by its technologic, impersonal and inflexible nature, does not allow the success of "jeitinho" as a strategy. The impersonal logic of call center is incompatible with the personal logic of "jeitinho". This confront result in emotional impacts on the client and does not fit itself in the Brazilian consumer marketing politic.

Key words: Brazilian “jeitinho", culture, identity, narrative, technology, context, work, consumer. 


\section{SUMÁRIO:}

1 - Introdução

2 - Pressupostos teórico-metodológicos 20

2.1 - Temas de Pesquisa 20

2.1.1 - As narrativas $\quad 20$

2.1.2 - Cultura e Jeitinho Brasileiro 27

2.1.2.1 - O Sistema Social Brasileiro e os Rituais de Identidade 28

2.1.2.2 - O Jeitinho Brasileiro 39

2.1.3 - O Contexto de Atendimento ao Cliente 46

2.1.3.1 - O Contexto de Atendimento no Brasil 48

2.1.3.2 - O Contexto de Call Center 49

2.2 - O Instrumental Teórico de Análise 51

2.2.1 - Análise da Conversa 52

2.2.1.1 - Unidades Formais de sentido e Organização Seqüencial da Conversa 54

2.2.1.2 - O Par Adjacente $\quad 55$

2.2.1.3 - Mecanismos de Coesão e Coerência 56

2.2.1.4 - A Expansão dos Pares Adjacentes 57

Pré- Expansões 57

Expansões por Inserção $\quad 58$

Pós- Expansões $\quad 59$

2.2.2 - Sociolingüística Interacional 59

2.2.2.1 - As Projeções Interacionais $\quad 59$

$\begin{array}{ll}\text { Footing e Rituais Conversacionais } & 61\end{array}$

A Teoria do Drama 64

A desconstrução das noções de falante e ouvinte 64

Projeções de footing e encaixes pela linguagem 68

Os processos de Ritualização $\quad 71$

2.2.2.2 - A noção de Enquadre $\quad 72$

2.3 - Metodologia de Pesquisa 76

2.3.1 - A natureza, fins e meios metodológicos 76 
2.3.3 - Procedimentos de análise de dados 79

2.3.4 - A caracterização do ambiente de pesquisa 80

2.3.4.1 - A Empresa $X$

2.3.4.2 - A Empresa tercerizada $Y$ e o cenário operacional do call center

As ferramentas tecnológicas $\quad 83$

Os operadores de call center $\quad 84$

3 - A Organização Geral da Interação Via Call Center 88

4 - O Desenvolvimento do Plot Narrativo na Interação Via

Call Center 96

4.1 - O Plot Narrativo $\quad 96$

4.2 - Os lugares da Narrativa na Interação 98

4.2.1 - A Narrativa no primeiro Slot Interacional 106

4.2.2 - A Narrativa no segundo Slot Interacional 123

4.3 - As funções da Narrativa na Seqüência Organizacional de Interação 136

5 - A Projeção da Narrativa na Interação Via Call Center 142

5.1 - O formato de Produção da Narrariva 142

5.2 - A Narração : dinâmica, elementos sócio-contextuais e a resolução do drama 150

5.2.1 - As situações de Família 152

5.2.2 - O dia a dia do Cliente $\quad 156$

5.2.3 - A Auto-projeção do cliente: o "eu" sofrido 159

5.2.4 - As Evocações Religiosas 160

5.2.5 - O Posicionamento do cliente e a humildade 163

6 - O Jeitinho Brasileiro 168

6.1 - As Narrativas como mecanismos rituais de Inversão e Neutralização. $\quad 170$

6.2 - Apresentação de Identidade e a busca de solidariedade 174 
6.3 - O ethos elocucional do Jeitinho: polidez, humildade, cordialidade, manha.

7 - Considerações Finais.

Referências Bibliográficas

Anexos 


\section{CONVENÇÕES DE TRANSCRIÇÃO}

\section{Símbolos Especificação}

.. $\quad$ Pausa observada ou queda no ritmo da fala, com menos de meio segundo

... $\quad$ Pausa de meio segundo, medida com cronômetro

.... Pausa

(1,5) duração da pausa acima de um segundo durante a fala, medida com cronômetro.

Descida de entonação

${ }^{\circ}$ palavra $^{\circ}$ trecho falado mais baixo

::: $\quad$ contigüidade entre fala de um mesmo falante ou de dois falantes distintos

? Subida leve sinalizando uma interrogação

, sobida leve, sinalizando que mais fala virá

sublinhado acento ou ênfase de volume

$\uparrow$ ou $\downarrow \quad$ subida ou descida acentuada na entonação, mais forte que os dois pontos

auto-interrupção

: $\quad$ Alongamento da vogal

:: ou ::: Duração mais longa da vogal

MAIÚSCULA Ênfase ou acento forte

----- $\quad$ Silabação (letra à letra)

( ) transcrição impossivel

( palavra) transcrição duvidosa

( ) Dúvidas, suposições, anotações do analista

$>$ palavras $<$ fala comprimida ou acelerada

$<$ palavras $>$ desaceleração da fala

hhh aspirações audiveis

.hhh inspiração audível

(h) aspirações durante a fala

[ Colchetes simples marcando o ponto de concomitância superposição de vozes (quando a concomitância de vozes se dá apenas em um dado ponto, com apenas um dos falantes dando continuidade à fala).

[ ] Colchete abrindo e fechando o ponto da sobreposição, com marcação nos segmentos sobrepostos - sobreposições localizadas.

$=\quad$ Dois enunciados relacionados, sem pausa na fala justaposta 
Oxalá se mostrou assim tão grande Como um espelho colorido a mostrar Pro próprio Cristo como ele era mulato Já que Deus é uma espécie de mulato Salve em nome de qualquer Deus, salve Se eu me salvei, foi pela fé Minha fé é minha cultura Minha fé, minha fé É meu jogo de cintura, minha fé (Marcelo Yuka - O Rapa) 